\title{
Energy Performance of a Heating System via Wastewater Management
}

\author{
Nicholas Hytiris, Konstantinos Ninikas, Bjorn Aaen \\ School of Engineering \& Built Environment, Glasgow Caledonian University \\ 70 Cowcaddens Road, G4 0AB, Glasgow, UK \\ N.Hytiris@gcu.ac.uk; kninik200@caledonian.ac.uk; baaen59@gmail.com
}

\begin{abstract}
In this paper, the actual heat energy output and economic performance of a heat pump are being stated. A recent installation of a water source heat pump (WSHP) at the Glasgow Subway Station, has been using the subsurface water ingress to provide heating and domestic hot water. The continuous water flow at a relatively high temperature enabled the system to operate with the same efficiency as a typical heat pump system, but with a reduced installation cost due to the non-existence of boreholes or trenches. The performance of this setup has been monitored for a short period and the coefficient of performance, as well as energy saving, is reported in the present paper. An average COP of 2,5 and a $60 \%$ energy input reduction for the heating system based on the old heating system's energy demand indicates the actual system's performance.

The output of this study indicates the financial benefit as well as the energy and carbon reduction of the heating system. It also highlights key issues which were encountered in such a challenging underground environment. Opportunities to further commercialize the excess heat energy output are explored.
\end{abstract}

Keywords: Wastewater Management, Environmental Sustainability, Renewable Energy.

\section{Introduction}

In the centre of Glasgow city, a circular underground passenger railway system has continuously been in operation since 1896 [1]. The system comprises of twin tunnels connecting fifteen stations along a route length of ten kilometres (Figure 1). Due to the age and methods of construction used in earlier times, a large volume of water from ground sources and surface watercourses enter the tunnel system. Such water ingress enters via weaknesses within the tunnel lining or installed drainage pipes and channels throughout the entire tunnel system. This is currently challenging due to its quantity that could potentially interfere with the subway operation and needs to be constantly managed.

Once water enters the tunnel network, the flows are directed to a number of pumping stations sumps either via a drainage channel set within the concrete trackbed between the running rails or via drainage pipes.

The water flow and water temperature measurements carried out over a 15 -month period at 21 different points within the network of the underground tunnels and platforms. The points of highest water influx were identified, and the heat energy content of each was calculated. Several options were identified for capturing the water from this shallow geothermal heat source and diverting it to a WSHP to recover heat. A final design for a pilot system within the tunnels was developed. The actual utilisation of this vast untapped resource to generate heat for one of the Subway stations was the main objective of the present study. Identifying the quantity and quality of this waste water in the Subway was critical, in order to examine the likelihood of harvesting heat energy with the use of a Water Source Heat Pump (WSHP). The aim was to establish the potential of using the water ingress in a Station with perennial flow. This would demonstrate the viability of such a heating system, reducing the installation cost due to the absence of boreholes or trenches which are typically associated with a conventional WSHP.

\section{Installation}

The field trial location was selected on the basis of four factors: distance (from the "source" to the "sink"), constancy of water flux; water quality, and water temperature. On this basis St. George's Cross Station was selected for the feasibility study (see location on Fig 1). 


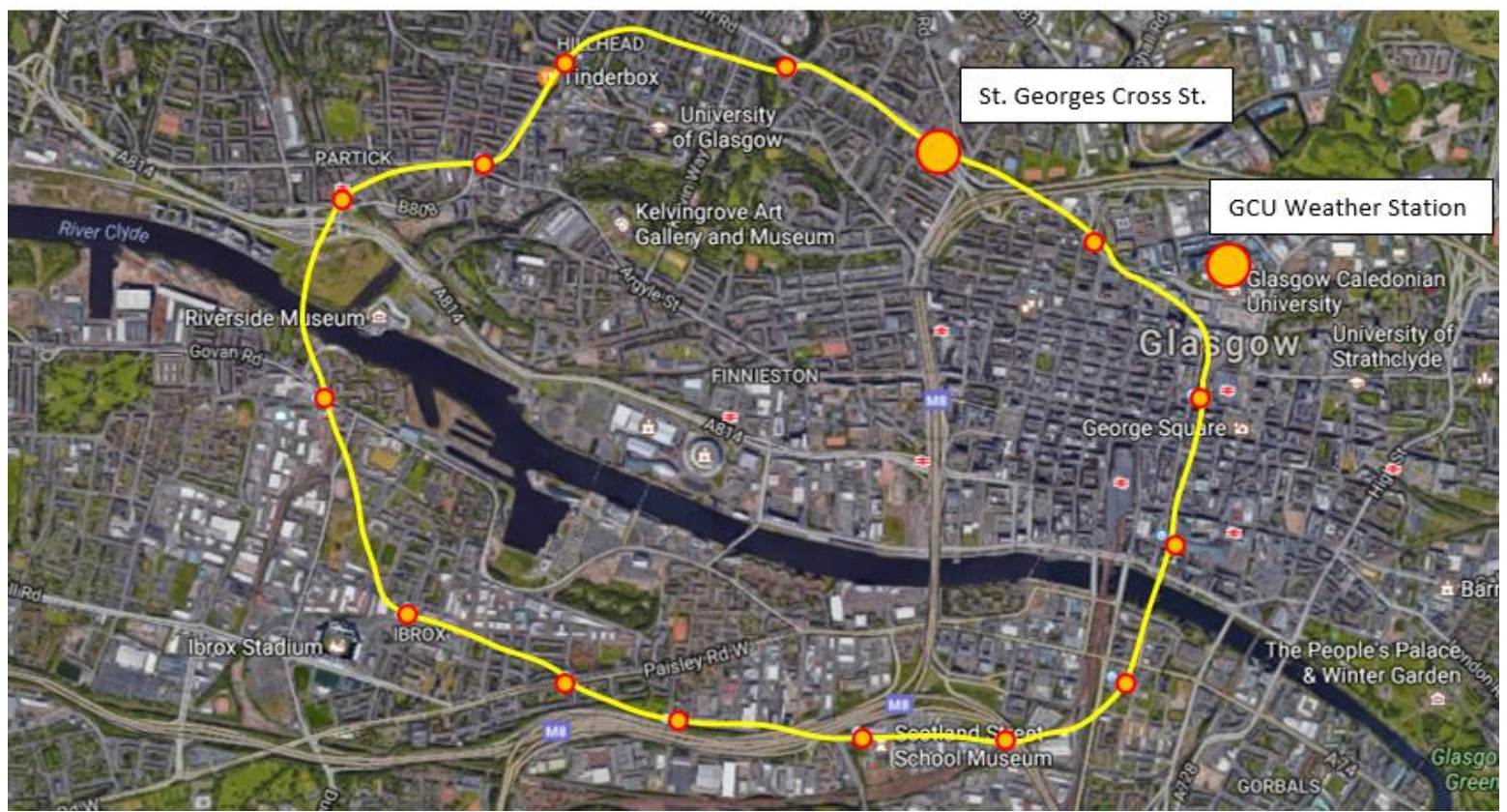

Fig. 1: The Glasgow Subway map and the trial Station, Source: Google maps.

The water temperature variations shown in Figure 2 (mean temperature $=14.2^{\circ} \mathrm{C}$ ) and the water flow rate at this station, shown in Table 1 (mean water flow $=2.75 \mathrm{l} / \mathrm{s}$ ) were the factors which allowed the trial heat pump installation.

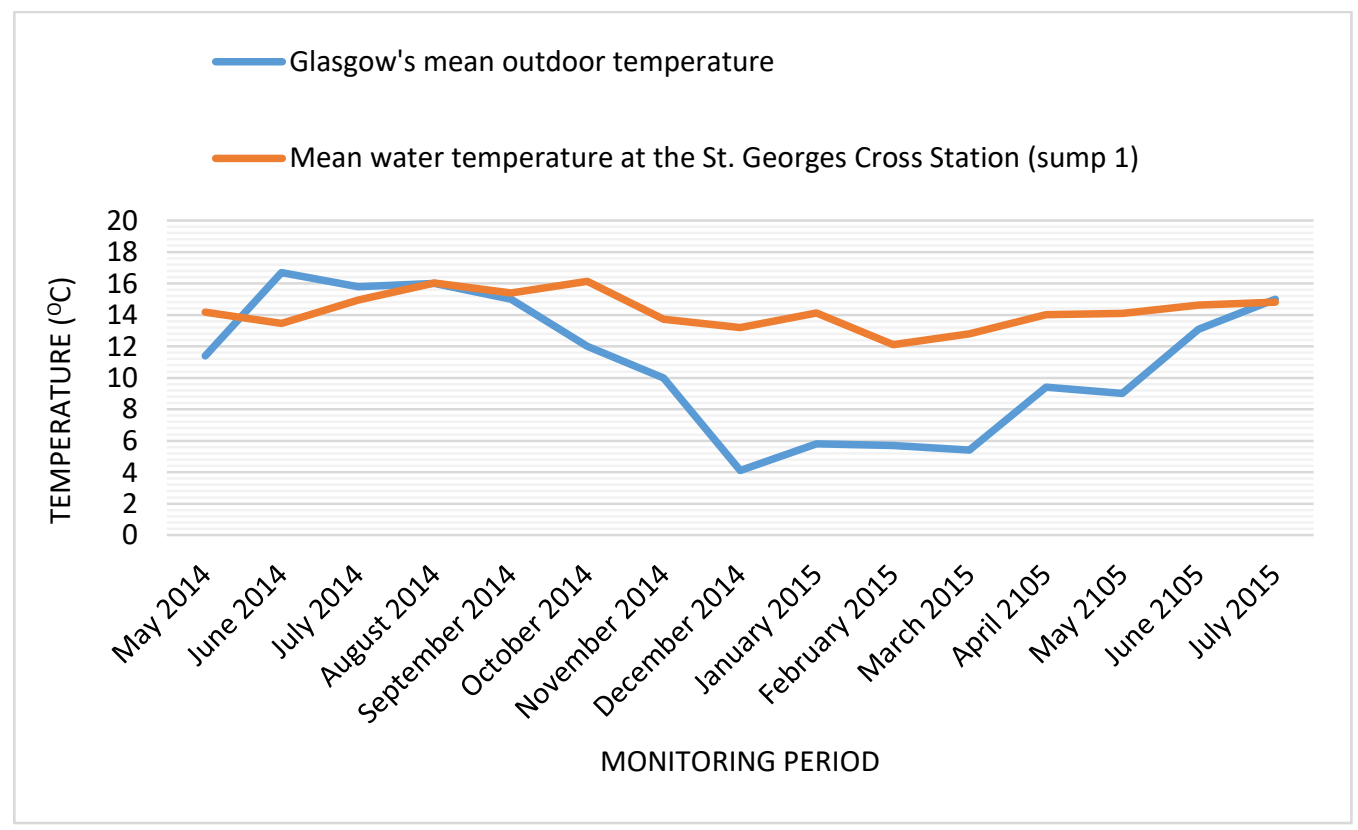

Fig. 2: The water temperature.

The water flow rate of some previous years was measured prior to the heating system's design in order to ensure that the minimum flow rate of $0,5 \mathrm{l} / \mathrm{s}$ which was required to operate the heat pump was always obtainable. The water temperature readings for the same period of time, established a relatively stable value which was expected to maintain the heat pump performance at a good level with the minimum operating temperature difference. This was designed and delivered on site in late 2015 and commenced operation in the last quarter of 2015. 
Table 1: Water flow at the trial Station.

\begin{tabular}{|l|r|r|}
\hline \multicolumn{2}{|c|}{ WF1: Water flow (Station St. Georges Cross) } \\
\hline Month & Year & WF1 (1/s) \\
\hline May & 2014 & 6.7 \\
\hline June & 2014 & 6.3 \\
\hline July & 2014 & 5.3 \\
\hline August & 2014 & 3.9 \\
\hline September & 2014 & 1.9 \\
\hline October & 2014 & 1.8 \\
\hline November & 2014 & 1.8 \\
\hline December & 2014 & 2.0 \\
\hline January & 2015 & 2.1 \\
\hline February & 2015 & 2.2 \\
\hline March & 2015 & 1.5 \\
\hline April & 2015 & 1.6 \\
\hline May & 2015 & 1.5 \\
\hline June & 2015 & 1.4 \\
\hline July & 2015 & 1.3 \\
\hline \multicolumn{2}{|l|}{ Average Flow } & $\mathbf{2 . 7 5}$ \\
\hline
\end{tabular}

The total heat load at the St George's Cross Station was calculated in $5.2 \mathrm{~kW}$ [2]. Thus, a 9kW WSHP was required to meet this station's heating and domestic hot water demand. Figure 3 shows the installed heat pump system. All equipment is constructed of non-combustible materials and cables are low smoke and fume, to comply with fire regulations [3]. 


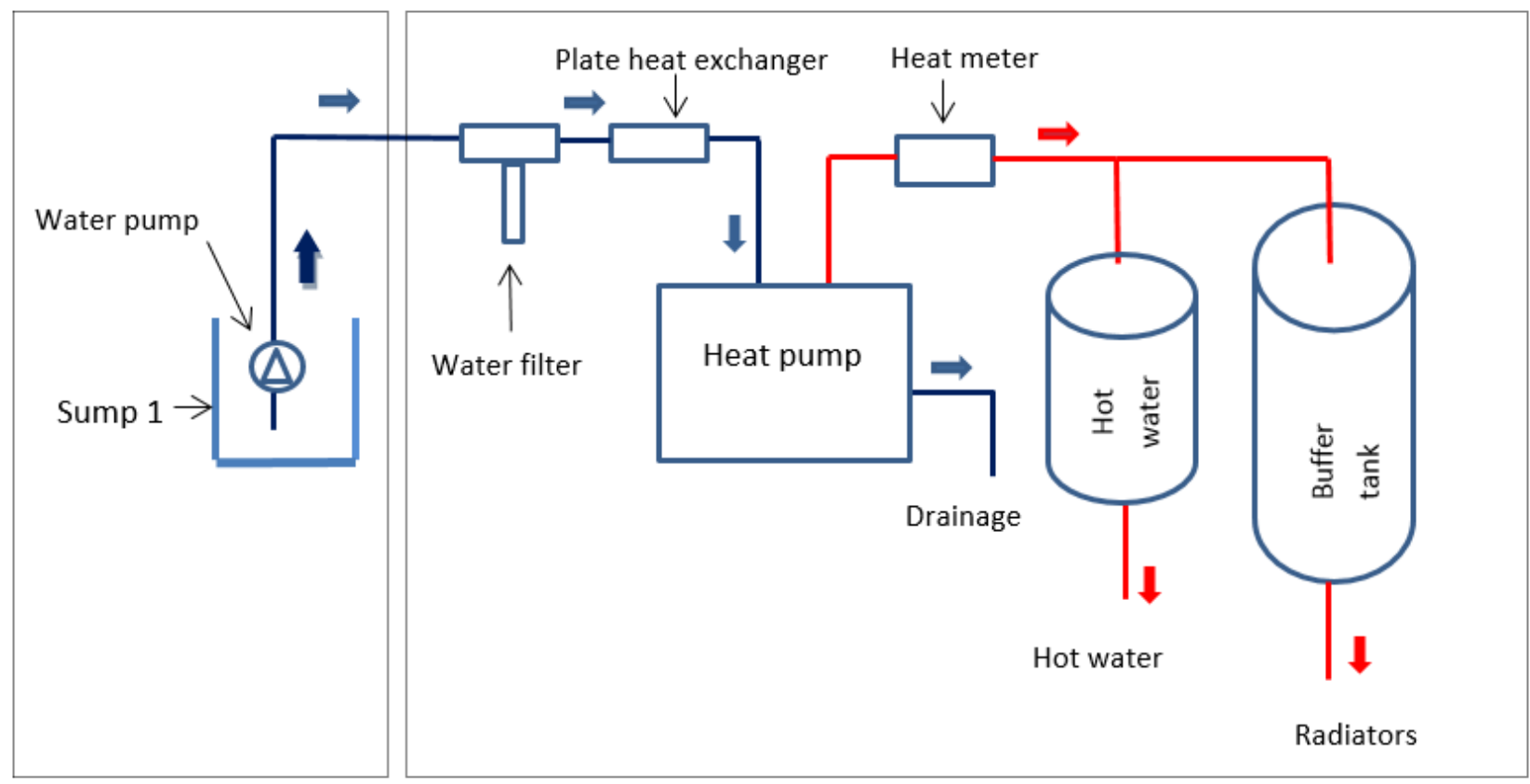

Track level

Cleaner's room - Ground floor

Fig. 3: Station's diagram of the heating system.

\section{System's Performance}

The heating system at the Station is operational 18 hrs per day for seven days a week. A buffer tank feed the station's hot water at 50 degrees Celsius. Once a week, the hot water system electrically raises the water temperature above 65 degrees Celsius to protect against Legionella disease. A room temperature of 21 degrees Celsius has been set and maintained during the operational hours at the station's premises.

In order to verify the above levels of performance a monitoring device was installed (heat meter) and readings obtained during the first 4 months of its operation. Figure 4 shows that there is an average heat energy output of $2.48 \mathrm{~kW}$ for each $\mathrm{kW}$ of energy input. The heat output includes both the hot water sent to the radiator coils as well as the water directed to the DHW buffer tank.

The current extraction of water from the WSHP system is $30 \mathrm{l} / \mathrm{min}$. This provides adequate heating and hot water to the station. One third of the water ingress at that specific section of the Underground System is being used for this heating system. The used water from the plant room is gravity-fed into the station's sewer. This has reduced the operation of the existing water pumps by a third, contributing to further cost savings both in terms of operation and maintenance of the pumps. The reason for extracting only a third of the sump's water was because that was all that was required to cover the Station's thermal needs. It would be possible to extract more heat from all of the water ingress provided a ready use for the heat could be found. 


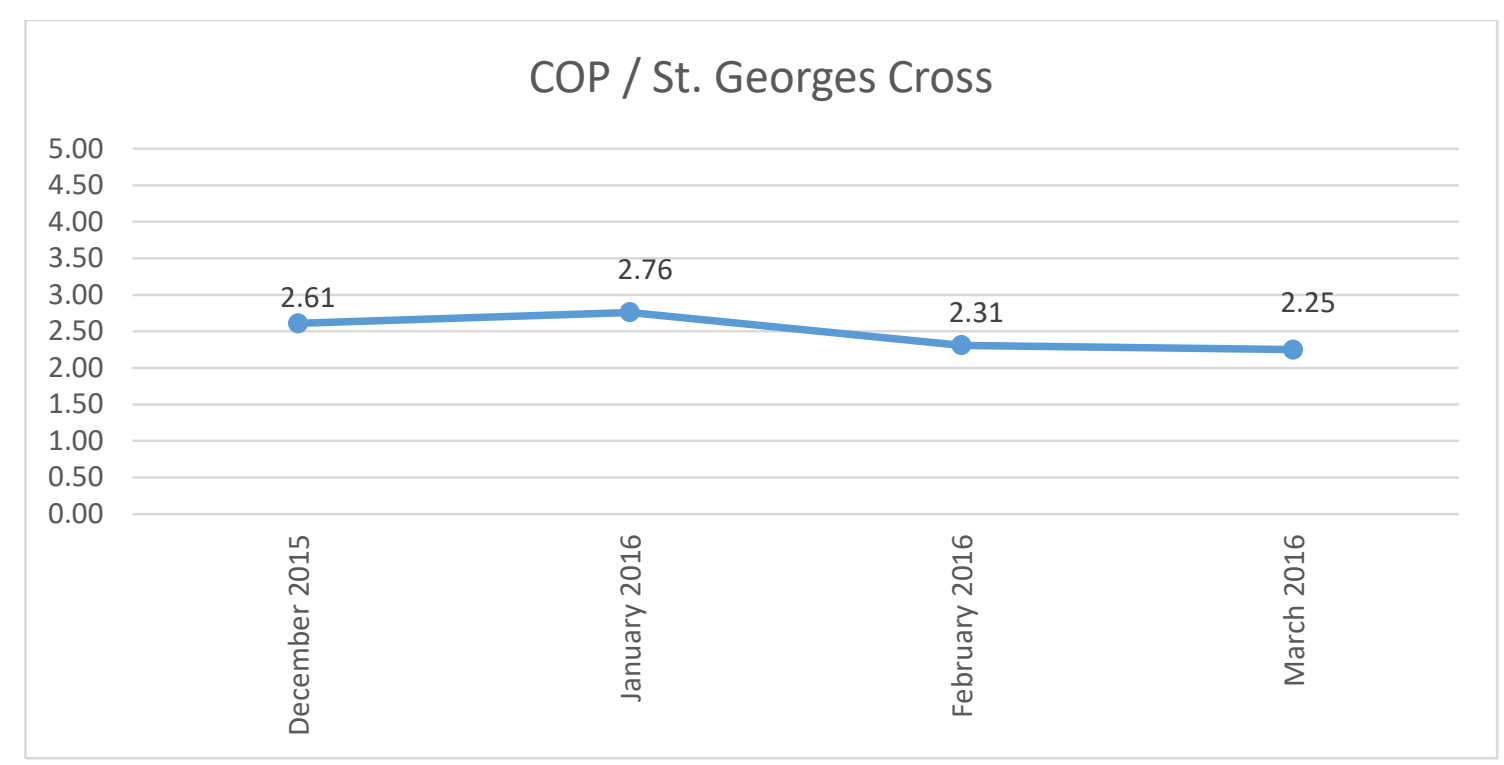

Fig. 4: The WSHP's Coefficient of Performance (Average $=2.48$ ).

Prior to the WSHP system, the station was heated by an electric fired heating system, which consumed $10 \mathrm{~kW}$ electricity for space heating only without including the energy input for the hot water. This has now been replaced with a $4 \mathrm{~kW}$ energy input (for a 9kW output of the WSHP). The new WSHP system provides not only space heating, but also domestic hot water. Thus a $60 \%$ reduction in energy consumption has been achieved, leading to substantial improvement in the station's carbon footprint.

\section{Conclusions}

Several valuable lessons were learned during the trial period. The first was the importance of stakeholder involvement and education. Staff familiarity and expectations of the new heating systems were an issue that posed operational difficulties at the beginning. During the first month of operation the staff began to compare the slow but steady heat provided by the WSHP against the quick-fire electric system they were used to, before the trial. They complained about the working environment being 'too cold', however, these concerns were resolved through training and information sharing on the heating principles of the new systems (i.e. Low grade but constant heat of the WSHP unlike an electric radiator, requires time to establish a steady ambient temperature).

After four months of the heating system's operation the system performance significantly dropped in March 2016. Diagnostics revealed that the heat exchanger was blocked with silt believed to have been caused by the tunnel upgrading work. A new heat exchanger together with a strainer (water filter) was therefore positioned after the completion of all works in November 2016.

The present empirical case study provides evidence that a WSHP system could be rolled out across the entire subway network. However, further steps are needed before this could be a reality. Given the high capital costs likely to be associated with the deployment of such a system across the network, feasibility studies on potential heat usage must be carried out to ensure the full economic benefit from the water ingress is made. This could be achieved through a district heating system using the renewable heat incentive (RHI) schemes currently in place in the UK [4]. Further integration with the heat mapping exercise currently underway in the region [5] is also needed to make this a reality.

\section{Acknowledgements}

This research was funded through a Knowledge Transfer Partnership (KTP) scheme operated by Innovate UK. The partnership members are Glasgow Caledonian University (GCU) and Strathclyde Partnership for Transport (SPT). 


\section{References}

[1] J. S. Shipway, "Centenary of the Glasgow Subway," in Proceedings of the Institution of Civil Engineers, Civil Engineering, vol. 114, no. 3, pp. 130-139, 1996.

[2] N. Hytiris, K. Ninikas, R. Emmanuel, B. Aaen, P. L. Younger, "A heat energy recovery system from tunnel waste water," Environmental Geotechnics, 2016. DOI: 10.1680/envgeo.15.00087

[3] Fire Precautions 2009. http://www.legislation.gov.uk/uksi/2009/782/pdfs/uksi_20090782_en.pdf

[4] Ofgem, Non-domestic Renewable Heat Incentive (RHI), 2017. [Online]. Available: https://www.ofgem.gov.uk/environmental-programmes/non-domestic-rhi

[5] Scottish Govt, Scotland's Heat Map, 2016. [Online] Available: http://www.gov.scot/Topics/BusinessIndustry/Energy/Energy-sources/19185/Heat/HeatMap 